\title{
HOMO HYGIENICUS: EDUCAÇÃO, HIGIENE E A REINVENÇÃO DO HOMEM
}

\author{
José GonçaLves Gondra*
}

Si les livres entraient dans les plus petits détails, on pourrait presque se passer d'experiénce. (Bacon) ${ }^{1}$

\begin{abstract}
RESUMO: O que os higienistas liam? O que faziam com o que liam? Ao explorar essa dupla indagação, trabalho com a hipótese de que os manuais adotados no tempo de formação dos médicos oitocentistas colaboraram para o delineamento e a confirmação da doutrina da higiene entre nós, que implicava, por exemplo, uma reordenação da idéia de medicina e de humanidade. Descrevendo o mundo que viam com base em um pêndulo no qual se marcava o certo e o errado, bem como o caminho que conduziria a um e a outro, os médicos formados na Corte Imperial, variando nas estratégias, incidiam, contudo, em objetivo assemelhado: produzir sujeitos higiênicos, higienizados e higienizadores. Grau de afinidade atingido graças ao que lhes era proporcionado, inclusive as leituras.
\end{abstract}

Palavras-chave: Educação. Higiene. Higienização.

\section{HOMO HYGIENICUS: \\ EDUCATION, HYGIENE AND MAN'S REINVENTION}

ABSTRACT: What did the hygienists read? What did they do with that information? Exploring this twofold question, I work on the hypothesis that the manuals adopted to train the Brazilian Eighteenth Century physicians contributed to delineate and confirm the hygiene doctrine among us, which entailed, for example, reordering the concepts of medicine and humanity. Describing the world they saw based on a pendulum that told right from wrong, as well as the ways that lead to one or the

Doutor em Educação pela Universidade de São Paulo (USP) e professor adjunto na Universidade Estadual do Rio de Janeiro (UERJ).E-mail: gondra@uerj.br 
other, these physicians graduated in the Imperial Court. However varied their strategies, they all pointed at a similar objective: producing hygienic, hygienized and hygienist citizens. Such degree of affinity was due to what they were supplied with, which includes their readings.

Key words: Education. Hygiene. Hygienization.

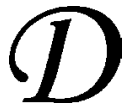

escrevendo o mundo com base em um pêndulo no qual se marcava o certo e o errado, bem como o caminho que conduziria a um e a outro, os médicos, inclusive aqueles formados na Corte Imperial, variando nas estratégias, incidiam, contudo, em objetivo assemelhado: produzir sujeitos higiênicos, higienizados e higienizadores. Grau de afinidade atingido graças a um horizonte de expectativas mais ou menos assemelhado, às experiências acumuladas dentro e fora do curso de formação e ao que aí lhes era proporcionado, inclusive pelas leituras autorizadas. Assim, caberia perguntar: O que os higienistas liam? O que faziam com o que liam? Ao explorar essa dupla indagação, trabalho com a hipótese de que os manuais adotados no tempo de formação dos médicos oitocentistas colaboraram para o delineamento e a confirmação da doutrina da higiene que implicava, por exemplo, uma reordenação da idéia de medicina e de humanidade.

Considerando a extensão dos elementos que participam de um programa de formação individual e/ou coletivo, nesse texto me fixo no quadrante das leituras prescritas aos futuros médicos, de modo que se possa extrair daí um modelo de formação seguido nos trópicos. No entanto, tal decisão não torna a proposta menos ampla e arriscada, já que, no rol das leituras, extensão e variedade são traços igualmente evidenciáveis. Desse modo, detenho-me no exame de dois autores de livros e manuais de higiene ${ }^{2}$ efetivamente consultados pelos estudantes de medicina, o que pode ser constatado pelas referências presentes em teses apresentadas no final do curso, sendo estas requisito e exigência para obtenção do grau de doutor. ${ }^{3}$ Precisando ainda mais o núcleo deste artigo, ancoro a reflexão em torno dos projetos voltados para a educação ou arte de dirigir a saúde e o desenvolvimento ${ }^{4}$ dos meninos e das meninas. Ao final, testo a permanência do discurso higienista como matriz dos projetos educativos, ocupando-me do exame de uma das obras do Dr. Kehl, médico eugenista brasileiro de intensa militância no início do século XX. ${ }^{5}$ 
Olhar e decifrar. Analisar e prescrever. Controlar e prever. Diagnosticar e predizer. Verbos que supōem atos, configurando, igualmente, uma gramática de práticas correlatas a uma ciência e a uma corporação. Constituídas e continuadamente reafirmadas nestes termos, a racionalidade médica reuniu argumentos, calculou procedimentos, investiu em técnicas, constituiu instituiçōes e fabricou tecnologias suficientes para produzir a ordem médica. Ainda assim, o quadro da doença e do sofrimento humano, particularmente no Brasil, contrasta com a sofisticação dos equipamentos materiais e simbólicos da chamada ciência das doenças ${ }^{6}$ já que dengue, febre amarela, cólera, malária e fome, dentre outras, perseguem, até os dias atuais, o cotidiano de fração expressiva da população brasileira assolada, igualmente, pelos anúncios de uma modernidade insuficientemente implementada e vivida ao sul do Equador. Modernidade que, segundo expressões da ciência médica, esbarra no continente do povo, que de longa data vem sendo plasmado sob o signo da rudeza e da falta. Tratar-se-ia portanto, nesta lógica, de lapidar uns e completar os demais de modo que se atingisse o modelo de homem civilizado que se pretendia impor. Para tanto, hospitais, presídios, hospícios, igrejas, cemitérios, quartéis, a casa e a própria escola foram sendo convertidos em pontos estratégicos por intermédio dos quais o programa civilizatório seria posto em funcionamento, conquistando lugares de enunciação, difusão e de realização de práticas a ele associadas. Arco ampliado, a ser construído em obediência aos princípios da higiene, ramo que, no processo de configuração da ordem médica, reivindicava para si a condição de principal. No século XVIII, Rousseau, em seu tratado de educação masculina, já chamara atenção para o fato de que "a única parte útil da medicina é a higiene" $\left(1995\right.$, p. 35). ${ }^{7}$ Tal reivindicação, contudo, atravessa o século XIX, ${ }^{8}$ prolongando e se atualizando no século XX, como evidenciado na Biblia da saude do eugenista brasileiro Renato Kehl. Segundo ele, era necessário propagar a afirmação "cartesiana" de que cumpria à medicina a solução dos problemas que mais interessam "á grandeza e á felicidade dos habitantes deste planeta", porque "só ela, pela higiene, o mais belo florão da sua coroa", 9 poderia promover o bem-estar físico e moral e a evolução somática e intelectual da humanidade. Ao apresentar a primeira "pílula da vida", ${ }^{10}$ o eugenista tropical, apoiando-se no francês Lacassagne, tratava de definir a higiene como: 
Arte de conservar a saude, e si é verdade, como diz a sabedoria antiga, que a saude é o primeiro dos bens, a hygiene deve ser a primeira das artes.

Sim é arte e não sciencia; representa a aplicação de todos os conhecimentos com o objectivo coordenado de proteger a saude, prolongando a vida dentro dos limites optimos de sua duração normal. E é arte victoriosa, conseguindo aos poucos expurgar o planeta das pestes, das infecções, sanear regiōes insalubres, valorizar o solo e beneficiar a vida humana em todos os sentidos. (Kehl, 1926, p. 16)

Com essa disposição, procurava-se caracterizar a medicina como uma verdadeira e efetiva ciência do social e, para fazer valer tal vontade, a higiene também se instalou no coração da formação médica, na forma de uma disciplina. Espaço e tempo a serem rentabilizados para formar ou moldar nos homens da ciência médica a sensibilidade de que seu ofício deveria conter a dimensão e perspectiva preventivas. Sob essa ótica, adquire pleno sentido a colonização das instituições e práticas sociais pelo saber médico, como pode ser observado no tratado de higiene privada e pública (Traité elementaire d'hygiene privée et publique) do médico parisiense e professor da Faculdade de Medicina de Paris, o Dr. Alfred Becquerel. ${ }^{11}$

Inicialmente apresentada como arte de conservar a saúde, a higiene é definida, em um segundo momento, como a ciência que trata da saúde com o duplo objetivo de sua conservação e aperfeiçoamento. "A higiene é aqui entendida dentro de seu sentido mais geral; nós a devemos compreender como a saúde individual e coletiva. A parte desta ciência que trata da saúde individual recebeu de modo generalizado o nome de higiene privada; e aquela que trata da saúde coletiva é chamada de higiene pública" (Becquerel, 1864, p. 1). ${ }^{12}$

Para o higienista francês, bifurcada no plano do indivíduo e no plano coletivo, a higiene não deveria ser percebida como a física e a química. Diferentemente destas, ela deveria ser percebida como uma ciência compósita, resultante da aplicação de diversas ciências e com um único objetivo: o estudo das causas capazes de modificar a saúde e os meios capazes de anular ou diminuir a ação mais ou menos nociva das referidas causas. Segundo ele, a higiene deveria ser concebida como aplicação de muitas ciências (física, química, história natural e patologia), às quais deveria fazer largos empréstimos e das quais dependia sua própria existência; ${ }^{13}$ traço que, por vezes, levou-a a ser representada como arte.

A bifurcação assinalada antecipa, de certo modo, os objetos recobertos pela "ciência compósita" e que são apresentados ao longo 
de seu tratado, o qual, organizado em duas partes e um apêndice, discrimina com precisão o "campo de aplicação" da higiene, como pode ser observado na estrutura da obra:

\section{Quadro 1}

(Estrutura do Tratado de Higiene Privada e Pública de A. Becquerel)

\begin{tabular}{|c|c|c|}
\hline \multicolumn{2}{|r|}{ Partes } & Capítulos/Classes \\
\hline I & $\begin{array}{l}\text { Tema da Higiene - estudo } \\
\text { do homem e estado da saúde }\end{array}$ & $\begin{array}{l}\text { 1- Definição e característica da saúde, 2- Idades, 3-Sexos, } \\
\text { 4- Constituição e temperamento, 5- Idiossincrasias, 6- } \\
\text { Hereditariedade, 7- Hábitos, 8- Raças, 9- Profissōes, e 10- } \\
\text { A iminência mórbida }\end{array}$ \\
\hline II & Matéria da Higiene & $\begin{array}{l}6 \text { Classes: }{ }^{14} \text { 1- Atmosfera, 2- Ingesta, 3- Gesta, 4- Percepta, } \\
\text { 5- Genitália, e 6- Excreta }\end{array}$ \\
\hline Apêndice & Higiene aplicada - Profissóes & $\begin{array}{l}\text { 1- Profissões intelectuais, 2- Militares, 3- Marítimos, } \\
\text { 4- Agrícola, 5- Mineradores, 6- Mecânicas, 7- Sedentárias, } \\
\text { 8- Expostos à temperatura elevada, 9- Higrométricas, } \\
\text { 10- Trabalho com matérias vegetais, 11-. Matérias animais, } \\
\text { 12- Matérias minerais, 13- Profissões nas quais é necessário } \\
\text { fazer uso de pulmões, laringe e olhos, e 14- Trabalho nas } \\
\text { manufaturas }\end{array}$ \\
\hline
\end{tabular}

Assim, incidindo na esfera pública e na esfera privada, a higiene buscava, com essa expansão e grau de detalhamento, justificar seu apelo em se fixar e ser reconhecida como o "mais belo florão" da medicina, apresentando-se como racionalidade que ao recortar o homem em si, nas várias relações com os demais e com o mundo do trabalho, tornava claro que pouco ou nada deveria ser deixado fora de seu alcance. Dessa ciência (ou arte) dilatada, para efeito deste trabalho, procuro observar a preocupação com a idade e com o sexo, aspectos integrantes e caros à doutrina higienista e intimamente entrecruzados com a questão educacional, realizada no espaço da casa e/ou no espaço dos colégios. Cruzamento também desenvolvido em dois livros escritos pelo professor da Faculdade de Medicina de Montpellier, o Dr. Fonssagrives (L'éducation physique des garçons e L'éducation physique des filles). ${ }^{15}$ Em forma de avisos/ conselhos/advertências, assemelhados aos dos manuais de civilidade, o higienista vai delineando um verdadeiro guia da boa educação física das meninas e dos meninos, unificando procedimentos no interior da ordem médica, de modo que a esta fosse reconhecida e admitida como a arte mais apropriada para dirigir comporta- 
mentos privados e públicos e, desse modo, legitimar-se como a ferramenta/instrumento mais eficaz para formação integral do homem.

Estruturados em torno de dez capítulos, os livros destinados a pais, mães, professores e professoras procuravam vulgarizar os fundamentos da higiene, apresentados na forma de preceitos a serem seguidos pelos responsáveis pela formação das novas gerações, no espaço público (os/as professores/as) e no espaço privado (pais e mães). Tais livros devem ser entendidos como parte de um ciclo de produção do autor, cuja meta era a de tornar a ciência acessível a todos, invadindo núcleos externos à ordem médica e, com isso, contribuir para legitimar a própria ordem de origem. Dois vetores que, apontando um para o exterior e outro para o interior da ordem médica, configuram atos solidários. Os livros aqui referidos são precedidos de um prefácio, sendo encerrados com um item de "provérbios, máximas e pensamentos" e com um sumário.

\section{Conselhos aos pais e aos professores}

Totalizando 368 páginas, $A$ educação fisica dos meninos ou conselhos aos pais de familias e aos professores é desenvolvido em torno de uma dezena de temas, sendo cada um deles iniciado com um prefácio: I- Instrução e higiene, II- A primeira educação, III- O endurecimento físico, IV- O colégio e a família, V- O problema escolar, VI- A educação das faculdades da criança, VII- A educação dos sentidos, VIII- A educação dos músculos, IX- A preservação dos costumes, X- A escolha de uma profissão.

Esse breve mapa de questôes permite confirmar a perspectiva de que as esferas pública e privada se encontravam sob o arco da higiene, com vistas a bem formar os meninos, a partir da difusão das luzes dos conselhos úteis e do combate ao acaso do empirismo e da rotina. Não bastasse a estrutura do decálogo para pais e mestres, a obra é encerrada com um conjunto de 91 provérbios, máximas e pensamentos aplicáveis à saúde e à educação dos meninos (p. 359-368). Quantidade que deixa evidenciado que os empréstimos da "ciência compósita" não se circunscrevem aos campos disciplinares explicitados por Becquerel, confirmando, contudo os objetivos por ele apontados.

No que se refere aos provérbios, cabe ressaltar que essa modalidade de discurso é constituída por sentenças de caráter prático e de uso popular, comuns a todo um grupo social, expressas de foram sucinta e geralmente ricas em imagens. Recorrer a esse tipo de discurso 
reforça a perspectiva de vulgarização da ciência da higiene, ao traduzi-la em sentenças comuns, ao mesmo tempo em que busca reforçar e imprimir maior autoridade às prescriçóes enunciadas, cujos indicadores seriam o grau e impacto da penetração de suas prescriçóes na ordem social. Aqui vale assinalar que até mesmo esse item é iniciado por um prefácio. Nesse caso, trata-se de um prefácio de Diderot, afirmando que "as sentenças são como pregos agudos que cravam a verdade em nossa lembrança". Caberia então indagar: Que verdades o Dr. Fonssagrives pretendeu cravar na memória de seus leitores? Ao lado dos conteúdos, a extensão das verdades, torna perceptível a perspectiva de fortalecimento dos argumentos médico-higiênicos.

Um adágio atribuído a Plutarco, o moralizador grego, é o primeiro da lista. Nesse, é afirmado que "as plantas regadas com moderação crescem facilmente, mas uma irrigação abundante sufoca a semente. Desse modo, a alma se alimenta e se fortifica por um trabalho bem administrado; o excesso abate e destrói suas faculdades". Moderação que supõe um conhecimento que regule a intensidade e regularidade do trabalho ao qual a alma deve estar submetida, já que, de acordo com um segundo pensamento de Plutarco, "o repouso é como o tempero do trabalho". Se o excesso é representado como prejudicial ao desenvolvimento dos meninos, a falta também não é menos contra-indicada. Nessa linha, o médico de Montpellier traz a contribuição de um pensamento de W. Temple em que se afirma que "os preguiçosos não deveriam ser classificados entre os vivos; eles são mortos que não podemos enterrar". Sobre a extensão do trabalho educativo, recorre a Rousseau quando este sentencia que "a educação do homem começa com o seu nascimento". Desse modo, apoiandose em Nicole, De Serres de la Tour, Locke, Silvio Pellico, Bacon, Franklin, Montaigne, na Bíblia, em provérbios franceses, chineses e alemães, dentre outros apoios, o autor quer fixar a tese da necessidade de uma educação que, na ótica de Montesquieu, tem menos a suprimir do que disciplinar. Processo educativo que deve ser guiado pelo princípio da moderação e da vigilância permanente, cujo exercício também deve ser uma responsabilidade dos pais. Nesta linha, a máxima de De Bonald vai nessa direção: "É difícil ao pai de família não olhar como um inimigo pessoal o autor de um mal livro que leva a corrupção para o coração de seus filhos". Isto é, o pai também deveria exercer um controle sobre os impressos/autores, na medida em que alguns eram adjetivados como leituras inimigas. No fim, o bom senso - o mestre da vida humana -, conforme o pensamento de 
Bossuet, seria adquirido caso as práticas educativas fossem sintonizadas com os princípios vulgarizados pela ordem médica, o que levaria à reconstrução da família e à unidade da ordem social.

Os adágios cumprem o papel de reafirmar a idéia de higienizar a família, central para o Dr. Fonssagrives. Para ele, era necessário mostrar que a educação é uma arte que não se improvisa, mas que se aprende, que não é bem-feita sem o concurso perseverante e simultâneo do pai e da mãe, estreitamente associados nessa grande obra e que deveria resultar na formação de uma inteligência sã, um coração direito, uma saúde vigorosa e do amor aos deveres, freqüentemente austeros. Enfim, o que se desejava alcançar era uma educação integral. ${ }^{16}$

\section{Conselhos às mães e às professoras}

Publicado um mês antes do livro dedicado à educação física dos meninos, o livro das meninas antecipa o padrão adotado naquele. ${ }^{17}$ Neste, também, após o prefácio, seguem dez capítulos em forma de "conversas", ou pílulas, como diria Kehl (1926), todos iniciados com epígrafes: I- Pequena e jovem menina, II- As funções da educação física das meninas, III- As sevícias da primeira higiene, IV- Exercícios físicos e jogos, V- A ginástica das meninas, VI- Os prelúdios da maternidade, VII- Beleza e limpeza, VIII- Instrução e trabalho, IX- Atitudes viciosas e desvios, e X-Distraçôes e prazeres. O livro, finalizado com 93 provérbios, máximas e pensamentos, integra, igualmente, uma linha de trabalho do autor, inscrevendo-se no rol das suas obras ${ }^{18}$ pelas quais procura popularizar o saber médico-higiênico. ${ }^{19}$ Para o Dr. Fonssagrives a higiene tem prediçôes particulares e bem justificadas para tudo aquilo que diz respeito ao augusto, mas difícil, ministério da maternidade. Remetia então à necessidade de realizar uma instrução prática das mulheres, posto que toda profissão, por mais fácil que pudesse parecer, exigia uma iniciação e a profissão maternal ${ }^{20}$ que, certamente, não é a menos complicada, nem a menos técnica por ser a mais comum, vinha sendo iniciada sem preparo e com uma intrépida ignorância verdadeiramente aflitiva. A mulher encontrava-se largada à própria natureza e se o autor reconhece e valoriza o instinto, também alerta para a existência de uma ciência da maternidade: "Sem o instinto, a maternidade seria um mecanismo frio, compassado e estéril; sem a ciência, ela seria uma empreitada apaixonada, plena de aventura e de perigos. A verdadeira mãe é a que ama e a que sabe. (...) É necessário que elas 
aprendam" (Fonssagrives, 1881, VII). A ciência maternal, por sua vez, era concebida em uma tripla ramificação: a higiene física, a moral e a intelectual, cujos objetos são, respectivamente, a saúde, o caráter e o espírito. Ao prefaciar seu livro dedicado à educação física das meninas nesses termos, o médico antecipa o conteúdo e a perspectiva da obra. Tratar-se-ia de fazer circular conhecimentos chancelados pela ciência de modo que se combatesse a ignorância das meninas e a fim de profissionalizá-las para seu trabalho futuro, modelando-as física, moral e intelectualmente, pois são consideradas a pedra angular da higiene, já que seriam as responsáveis por vigiar e dirigir a educação física das futuras filhas.

O protocolo geral do livro encontra-se reforçado na seção dos provérbios, máximas e pensamentos, também iniciado com a metáfora dos "pregos agudos" de Diderot. Distintamente do livro dos meninos, em que autoras não são referidas, a primeira máxima é de autoria de uma mulher, Mme. De Necker-Saussure, afirmando não ser necessário exagerar o papel do sentimento. As sentenças selecionadas legitimam o programa médico para a educação das meninas. Nessa linha, os autores, como no caso da educação física dos meninos, também são variados, destacando-se, nesse caso, a presença de máximas de mulheres. Além daquela que inicia a lista, temos também Mme. De Gasparin, Mme. De Stael, Mme. De Swetchine, Mme. Lambert e Mme. Geofrin. Essas figuram ao lado de Montaigne, Franklin, Fenelon, Ménage, Bacon, Voltaire, Platão, La Fontaine, provérbios de origens variadas, excertos da Bíblia e Rollin, para indicar alguns. Este último, ao encerrar a lista, sintetiza com muita precisão o projeto do livro, ao afirmar que um dos primeiros cuidados de uma mãe é o de se instruir de tudo o que fosse necessário para bem educar seus filhos. No livro, as mães e professoras, destinatárias privilegiadas da escrita do Dr. Fonssagrives, encontrariam o necessário.

Criticando a vaidade, valorizando a instrução, denunciando a moda, enfatizando o poder da mulher, ressaltando a importância das forças morais, destacando o papel dos bons livros, fixando o objetivo da educação feminina, assinalando a função das regras e criticando o sedentarismo, dentre outros pontos, o higienista vai delineando o programa a ser seguido pelas mães e professoras. Estas deveriam ensinar, mas também funcionar como exemplo, visto que "a lição inicia e o exemplo aperfeiçoa", de acordo com a máxima de Lamotte. 


\section{Conselhos à sociedade}

Difundidos e apropriados no âmbito da corporação médica, os preceitos médico-higiênicos não deveriam ficar circunscritos a esse espaço. Tratava-se, nesse lugar, de uma formatação mínima, de modo que se assegurassem procedimentos mais ou menos homogêneos por parte da corporação, com vistas a fazer valer a perspectiva uniformizadora desse saber. Esse é, portanto, um aspecto da estratégia formulada pela ordem médica. Outro aspecto consiste na ampliação das possibilidades de irradiação, atingindo a população de forma mais ampliada. Desse modo, na imprensa, na literatura, nas belas-artes e nos tratados/dicionários médicos é possível atestar a ampliação do auditório a ser constituído pelo discurso higienista. No Brasil, essa tradição pode ser evidenciada por intermédio das produçōes do Dr. Kehl, ${ }^{21}$ ao escrever $A$ fada hygia - $1^{\circ}$ livro de hygiene, $O$ médico no lar - Dicionário popular de medicina de urgência, Eugenia e medicina social, Melhoremos e prolonguemos a vida, A cura da fealdade, Como escolher um bom marido - conselhos às moças, Como escolher uma boa esposa e Biblia da saude, por exemplo, nas quais procura fazer circular tal perspectiva. O primeiro livro desta lista é apresentado como "última novidade em livro escolar", visto que, com ele, poder-se-ia aprender higiene aprendendo-se a ler, traço que o faz ser destinado a todos os professores e às mães. Já o último, dedicado à esposa e colaboradora, aproxima-se do modelo fonssagriveano, encontrando-se organizado em 23 capítulos, contendo cada um deles várias "pílulas". O último capítulo é composto por 73 pílulas ou provérbios, máximas e pensamentos. Aqui, gênero e idade comparecem apenas como mais um critério, pois o que efetivamente se deseja é produzir o aconselhamento da sociedade, empregando-se, para tanto, "as sentenças, rifōes ou anexins", fórmulas simples e concisas que excitam a imaginação. Segundo o Dr. Kehl, há ditos sentenciosos e curtos, resumindo verdades singelas, de elevada significação, amadurecidos através de séculos e joeirados no crivo apertado do senso popular. ${ }^{22}$ Para ele:

Certas sentenças valem, também, pela graça intelligente ou pelo chiste que encerram; numa contestura succinta de palavras, formulam, laconicamente, decisões precisas. Quando citadas com propriedade e opportunidade, rematam uma divergencia ou traçam a directriz de um conceito justo, de modo irreplicavel.

As sentenças são vivas e luminosas e correm o mundo como a affirmação do velho adagio "vox populi, vox Dei”. (1926, p. 461-462) 
Assim, recolhendo a voz de Deus, via voz do povo, o médico esforça-se por inscrevê-la na ordem do discurso médico-higiênico, incorporando os "ditados" e atribuindo-lhes a voz e o estatuto da ciência, motivo que o faz pedir aos jovens a atenção refletida de alguns minutos para as paremias selecionadas e que, segundo ele, encerram, sob a forma sintética, clara e precisa, grandes verdades e valiosos conselhos.

Recobrindo o espaço íntimo, da casa e da família; incidindo nas atividades de professores e professoras; expandindo seu alcance para a sociedade mais ampla, encontramos a racionalidade médica em plena movimentação sem, contudo, descuidar do território mais próximo, isto é, o espaço-tempo de formação dos futuros doutores. Nos trópicos, lendo franceses, buscava-se operar uma efetiva modelagem, equipando os jovens acadêmicos dos largos fundamentos da doutrina higienista. Bem formados, esperava-se que esses homens agissem como efetivos médicos da ordem social, avaliando, diagnosticando e formulando o receituário a ser seguido. Tal procedimento, constituído em estratégia, funcionou de modo eficaz no processo de construção de legitimidade da própria ordem médica.

Com esse esforço, a educação é convertida em caminho privilegiado para fazer disseminar a perspectiva higienista e higienizadora. Por seu intermédio, guiada pela matriz médico-higiênica, a humanidade poderia ser reinventada, dando origem a uma nova espécie: o Homo hygienicus. Utopia cunhada sob o signo da razão que, até hoje, contrariando os iluministas mais otimistas e radicais - das grandes verdades e dos valiosos conselhos -, tem demonstrado ser insuficiente para promover de modo igualitário o tão perseguido e tão sonhado projeto higienista.

\section{Notas}

1. Epígrafe do Dictionnaire de la santé ou repertoire d'hygiene pratique a l'usage des familles et des écoles, de J. B. Fonssagrives (1876).

2. Trata-se dos higienistas franceses Alfred Becquerel e Jean Baptiste Fonssagrives.

3. Cf. Gondra (2000).

4. Cf. Fonssagrives (1870).

5. Aqui não me ocupo de explorar aspectos teóricos da doutrina da higiene e da eugenia. Cabe, no entanto, assinalar que a legitimidade da primeira cria as condiçóes para o aparecimento da segunda, havendo entre ambas complexas relações de empréstimos e diferenciaçôes, cujo estudo escapa aos objetivos deste artigo.

6. A respeito dessa definição, cf. Luz, 1996. 
7. Ao dialogar com Locke sobre essa questão, o autor suíço assinala: "O sábio Locke, que passara uma parte da vida estudando medicina, recomenda enfaticamente que jamais se dêem remédios às crianças" (p. 34). Com isso, critica o modismo da medicina ou iluminismo médico, verificado à época. No que se refere às preocupações de Locke com a educação, estas podem ser conferidas em sua obra Quelques pensées sur l'éducation (1966).

8. A respeito dessa tradição na França e no Brasil, cf. Gondra (2000). Para o caso português, cf. Pereira \& Pita (1993) e Ferreira (2000).

9. Grifos meus.

10. O livro é constituído por conselhos e preceitos farmacologicamente divididos em pequenas doses ou capítulos-pílulas ou pílulas-capítulos, para serem ingeridas pelos olhos e digeridas pelo cérebro. De acordo com seu autor, no lugar de Biblia da saude, melhor intitular-se-ia "Pilulas da vida" se a crítica não o considerasse irreverente à sisudez da ciência. A primeira pílula é designada de "a arte de conservar a saude".

11. Aqui faço uso da $3^{a}$ edição revista e ampliada, sob a responsabilidade de M. Beuagrand, publicada em 1864; isto é, 10 anos depois da $2^{\text {a }}$ edição e 13 anos após a $1^{\text {aa }}$, publicada em 1851. Recusando a idéia de que seu livro fosse visto como uma "simples compilação", A. Becquerel afirma que este incorporava algumas idéias pessoais, de suas pesquisas e de numerosas e novas aplicações médicas. Isso não implicava, contudo, ausência de diálogo com os tratados de higiene da época. $\mathrm{O}$ acesso à edição com a qual trabalhei se constitui em uma dívida que tenho com Fernanda L. Paiva, a quem agradeço a delicadeza e generosidade do gesto. Para efeito de contraponto acerca da questão da fixação dos campos da higiene em Portugal, cf. Pereira \& Pita (1993) e Ferreira (2000).

12. Grifos do autor; tradução livre.

13. Baseados no estudo de Laplantine, poderíamos afirmar que os empréstimos não se restringem ao campo das ciências, mas também ao religioso. Já o estudo de Foucault nos permite perceber articulaçôes com a ordem militar, sobretudo nos procedimentos táticos e estratégicos do campo médico. A esse respeito, cf. Foucault, 1987, p. 151.

14. As seis classes encontram-se distribuídas em 30 capítulos (calor, luz, eletricidade, influências siderais, ar atmosférico, sol, águas, climas, habitações, vestimentas, cosméticos, banhos, vírus, natureza dos alimentos, condimentos, conservação das substâncias alimentares, alimentos tóxicos, regime, bebidas, proteção e coloração dos alimentos, exercícios/movimentos, exercícios combinados ou exercícios especiais, sentidos externos, sentidos internos, das faculdades intelectuais propriamente ditas, das paixões, do sono, do casamento e do celibato, fecundidade/esterilidade, e prostituição e pederastia.

15. Cf. Fonssagrives, 1870 e 1881.

16. Acerca da chamada educação integral (física, moral e intelectual), cf. Gondra (2000).

17. Trabalhei com a edição de 1881 , embora esse livro tenha sido publicado pela primeira vez em abril de 1870 .

18. Entretiens familiers sur l'hygiène e Le rôle des mères dans les maladies des enfants, por exemplo.

19. O projeto de difusão dessa perspectiva pode ser percebido na quantidade de obras publicadas com esse caráter. Além das obras desse higienista francês, a permanência dessa estratégia pode ser conferida nas obras de Lacassagne (1879), Cryns (1904) e Kehl (1926), por exemplo.

20. Grifos do autor. 
21. Fundador, no Brasil, da primeira sociedade latino-americana de eugenia, membro da Academia Nacional de Medicina de Lima e da Societé Française d'Eugenique de Paris, por exemplo. A respeito da participação desse médico em defesa da eugenia, cf. Marques, 1994.

22. Apoiando-se em Tobias Barreto, o médico considera a ciência dos provérbios, ou paremiologia, a mais alta expressão da sociologia.

\section{Referências bibliográficas}

BECQUEREL, A. Traité elementaire d'hygiene privée et publique. Paris: P. Asselin, 1864.

CRYNS, J. Guide populaire d'hygiene. Bruxelles: A. Manceaux; Paris: Scheiler Frères, 1904.

FERREIRA, A.G. Gerar, criar, educar: a criança no Portugal do Antigo Regime. Coimbra: Quarteto, 2000.

FONSSAGRIVES, J.B. L'éducation physique des garçons ou avis aux pères et aux instituteurs sur l'art de diriger leur santé et leur développement. Paris, 1870.

FONSSAGRIVES, J.B. Dicitionnaire de la santé ou repertoire d'hygiene pratique a l'usage des familles et des écoles. Paris: Charles Delagrave, 1876.

FONSSAGRIVES, J.B. L'éducation physique des filles ou avis aux mères et aux institutrices sur l'art de diriger leur santé et leur développement. Paris, 1881.

FOUCAULT, M. Vigiar e punir: história da violência nas prisões. Petrópolis: Vozes, 1987.

GONDRA, J.G. Artes de civilizar: medicina, higiene e educação escolar na corte imperial. 2000. 2v. Tese (Doutorado em Educação) - Faculdade de Educação, Universidade de São Paulo, São Paulo.

KEHL, R. Biblia da saude (Hygiene). Rio de Janeiro: Francisco Alves, 1926.

LACASSAGNE, A. Précis d'hygiene privée et sociale. Paris: Masson, 1879.

LAPLANTINE, F. Antropologia da doença. Trad. Walter L. Siqueira. São Paulo: Martins Fontes, 1991.

LOCKE, J. Quelques pensées sur l'éducation. Trad. de Georges Compayré. Paris: J. Vrin, 1966. 
LUZ, M.T. A arte de curar versus a ciência das doenças: história social da homeopatia no Brasil. São Paulo: Dynamis, 1996.

MARQUES, V.R.B. A medicalização da raça: médicos, educadores e discurso eugênico. Campinas: UNICAMP, 1994.

PEREIRA, A.L.; PITA, J.R. Liturgia higienista no século XIX: pistas para um estudo. Revista História das Idéias, Coimbra, v. 15, 1993.

ROUSSEAU, J.-J. Emílio ou da educação. Trad. de Roberto Leal Ferreira. São Paulo: Martins Fontes, 1995. 